\title{
Triad of innovative development: universities- municipalities-business in the development of territories based on cluster policy: case of France
}

\author{
Elena Ponomarenko ${ }^{1,2, *}$ \\ ${ }^{1}$ RUDN University, Miklukho-Maklaya Str., 6, 117198 Moscow, Russia \\ ${ }^{2}$ RANEPA, Vernadskogo Pr., 82, 119571 Moscow, Russia
}

\begin{abstract}
Having conducted a comparative analysis of higher education and science reforms in France and in Russia in recent years, we have concluded that with obvious progress in a number of areas of reform, the link between education and science and the implementation of their innovative results in practice is significantly more successful in France. This connection is implemented within the framework of cluster policy, the development of poles of competitiveness and technopolises. They became the basis for promoting a new economic model of development based on the knowledge economy in the early 2000s. A new impetus to the rapid development of clusters in European countries was given by the processes of digitalization, which penetrated into all spheres of activity - research, education, commercialization of ideas, production of new products. The closest connection between science (University and academic science), education (higher educational institutions, their laboratories) and the development of territories (primarily cities) with the help of digital technologies is becoming an everyday reality, the engine of social progress. The growth points that appeared in different regions, expanding within the framework of projects that were selected on a competitive basis and supported by the state, showed the successful result of a targeted policy of supporting innovation, helped to find a way to get the economies of a number of European countries out of the permanent crises of the late 90s, 2008-2009. What is the secret of the success of cluster policy in France? Which role does each of the leading players in the cluster play? Who is the coordinator, connecting link - government institutions? Universities? Research laboratories? Companies? What unites clusters, poles of competitiveness and technology parks? This article is devoted to the answers to these questions.
\end{abstract}

\section{Introduction}

As we know from economic theory and confirmed by the practice of recent decades, there are not so many drivers and stimulators of economic growth. This is either a powerful

*Corresponding author: elponamorenko@yandex.ru 
investment in the economy - 30-40\% GDP (the example of China, India), growth in exports of products, primarily high - tech (the example of the «Asian tigers» - South Korea, Taiwan, Singapore, Japan), or growth in domestic demand (the example of Russia between 2000-2008 - about $10 \%$ per year), with an increase in exports of hydrocarbons.

Export growth and a positive foreign trade balance have always been signs of a «healthy» economy. At the same time, the developed countries of Europe were the first to face the problems of depleted natural resources (their overuse), which are always in demand on world markets, which forced these countries to search for alternative sources of economic development and growth at the very beginning of the years 2000 .

The key source was the production and export of high-tech innovative products. This is not just a product (service) of single enterprise, the technological innovation implies the existence of a modern «factories of the future» on the basis of the triple alliance of science and education in the face of universities, government (regions and municipalities), business (from large to small) that implement the process of bringing advanced scientific research to industrial designs, creation of innovative products, competitive not only in domestic market but also in external. Innovations have decisively taken the place of a driver of economic growth in today's globalized economies.

The concept of the «triple helix» was developed in the late 90's by H. Etzkowitz and L. Leydesdorff on the basis of the transition from the dual relationship «state - business» in the industrial economy to the triple - «University-business-state» in the knowledge economy. The new role of universities (in addition to the traditional tasks of teaching and research, it also involves the transfer of technologies and innovations) is also justified in the concept of the «third mission of universities» by Burton R. Clark and in the famous book by J. Wissema «New generation University» [1] [2].

The triple helix, with the support of the state and the local community, gives stability to both national and, most importantly, regional development, and is implemented on the basis of cluster policy. Clusters - are not individual companies or breakthrough research organizations, but a new network phenomenon that has united scientific, educational, and industrial organizations in a single area under the patronage and support of government agencies. Such networks have become able to produce and introduce the latest ideas, patents, and create innovative products that are so necessary to give dynamism to the territorial economy in Europe.

Clusters have united three aspects: research, political and economic. Research - is the connection with universities, as conductors of new knowledge, their research laboratories; political - the attraction of regional (municipal) political elites to the idea of territorial development, economic - finding investors for progressive innovative products.

Digitization processes have given an additional impetus to the rapid development of clusters, poles of competitiveness, and technopoles in European countries. Based on the use of digital technologies, regional growth points are becoming more widespread - smart homes, smart districts, smart cities.

Balanced modern territorial development, including the creation of «smart» cities, is impossible without the participation of educational and scientific institutions located in a particular area. In this regard, it is becoming more relevant to study the new role of universities in the development of territories, their relationship with local government and the business community.

The forms and methods of successful coordination of joint efforts of numerous organizations in clusters, poles of competitiveness in a tough international market competition are the subject of close study of researchers and practitioners of cluster policy, implemented since the 2000s in developed countries: Spain, Germany, Austria, Japan, the United States, and France. 
Numerous studies have been devoted to the evolution of cluster development. It is based on the ideas of Alfred Marshall about «industrial areas», based on the study of the phenomena of Birmingham and Sheffield in England at the end of the 19th century. Later, there were Italian competition districts, and then - clusters, the theoretical justification for which was given by Michael Porter. Thanks to him, since the late 90s of the twentieth century, clusters have been explained as a geographical concentration of economic activity, production networks generated, on the one hand, by competition that encourages the development of innovations, and on the other hand - by the cooperation of organizations included in the cluster (exchange of information through official and unofficial contacts), which leads to the spread of innovations. Public and private investors play an important role in the implementing of cluster policy, which requires significant investment, according to Porter. Clusters are not necessarily formed with significant state support, but M. Porter justifies state intervention for the development of wide, competitive clusters (Silicon Valley, Boston's Route 128, etc.) [3].

\section{Materials and methods}

The paper provides qualitative analysis of the development and specifics of cluster policies in France. The methodology is based on the principles of formal logic and systemic analysis. The methods of generalization, analysis and synthesis were also used. The research paper and databases are used as a source of information.

To assess this problem we analyzed implemented policies and other different factors influencing the state of cluster developing.

\section{Results and discussion}

The success of cluster initiatives has inspired many economic strategies and given impetus to the development of country cluster policies. It is particularly interesting to examine the experience of France's cluster policy, where several hundred cluster initiatives with direct state support have passed a number of stages of development since 2004, have grown into several dozen (about 70 in 2019) poles of competitiveness (PC). Understanding of the importance of updating industrial policy based on investment in innovation, new technologies, by encouraging the transfer of innovation from research laboratories to industrial companies came to France in 1995 . However, only since 2004, cluster policy has been developing, which has gone through several stages of evolution.

At the first stage of cluster development (2004-2008), the state was the initiator. The first stage is characterized by strong state support based on competitive selection, serious competition between cluster initiatives (innovative projects in various fields of activity and different geographical regions).

At the first stage, more than 1000 projects participated in the competitive selection process, and 1,5 billion euro of public funds were invested in the selected innovative projects.

Clusters were rapidly gaining strength in the context of Internet penetration in all spheres of life, specializing primarily in everything related to innovation: digitalization, telecommunications, logistics projects, microelectronics, biotechnologies, etc.

Having played a positive role in giving dynamics to territorial development, showing examples of efficiency, clusters gradually concentrated around the poles of competitiveness (PC). The poles of competitiveness are specialized operators, qualified intermediary structures that search for innovations, unification of professional participants in their development and implementation, and investments for the implementation of innovations. Along with the poles of competitiveness, as a form of state support for clusters, there are other mechanisms for the development of territorial cooperation - clusters of enterprises, 
territorial poles of economic cooperation, centers of excellence in rural areas, innovative poles for artisans, mechanisms for partner research, etc.

At the next stage - in 2009-2012 - issues of strategic management of the poles of competitiveness, accelerated implementation of innovative platforms for venture financing, stimulating the growth of small and medium-sized enterprises (SMEs), investment in the ecosystem of innovative development (social, transport, digital, technological, environmental infrastructure) were being resolved. At this second stage, more than 1,5 billion euro were also spent, but already with the involvement of business resources.

Since 2013 to date, poles of competitiveness have been developing from design to implementation factories, strengthening the partnership of participants, creating centers for the transfer of cluster technologies. The movement «for open innovation» is becoming not just an emotional appeal, but an urgent need for mutual disclosure of information in order to achieve effective results. The European strategy «Europe 2020», dedicated to promoting «smart growth» (including bringing research funding to 3\% of GDP), claims that success now does not depend on the efforts of a single firm, but is based on the exchange of research results and knowledge among all cluster participants.

At the end of the second stage, it was concluded that the policy of creating poles of competitiveness has reached its goal, 85 technologies with «high potential for industrial development» were identified in 2010 as key points by 2015-2020. These are the aviation industry (Aerospace Valley, Astech, Pegase), railway (iTrans), automobile (iDForCar, Véhicule du Futur, LUTB, Moveo), pharmaceutical industry (Medicen, Lyon Biopôle, Eurobiomed), agriculture, food industry and information-computer technology (Systematic, Images et Réseaux, Minalogic, Cap Digital). The poles of competitiveness cover both the service sector (finance, logistics) and environmental technologies, as well as the agricultural and agro-industrial sectors.

In 2014, about 8,500 member companies and 1,150 public research and educational institutions joined and collaborated in the 71 poles of competitiveness in France. [4]

Currently, the third stage of cluster development has been completed (2013-2017) and the fourth stage has begun in 2018. Cluster policy instruments and financial flows have changed significantly - innovative products and technologies are initiated and implemented in the current poles of competitiveness with the institutional support of government structures, but often without the financial participation of the state.

Since $2017,50 \%$ of all innovative companies, all companies of the national exchange index CAC 40 and state research structures are included in the poles of competitiveness. $70 \%$ of research organizations in the PC have partnerships with small and medium - sized enterprises, $59 \%$ - with large enterprises.

In 2019 France ranked first in Europe in terms of the number of new startups, flows of investment in innovative products, and a high share of innovation, surpassing recognized leaders in this area - both Germany and the United Kingdom. At the same time, it is noteworthy that the share of private investment in total investment in innovative products is more than $70 \%$, and the share of public (local) funds is more than $25 \%$, while the share of universities is only about $5 \%$.

By now, France has become one of the leading countries in the field of research and innovation. The key indicators of 2017-2020 are listed below [7]:

1) France is ranked 9th most innovative country in the Innovation Index (Bloomberg 2018), with South Korea leading, followed by Sweden.

The French Alternative Energies and Atomic Energy Commission (CEA) ranks 1st in Europe and 2nd in the world in the 2017 ranking of the most innovative public organizations (Thomson Reuters ranking).

18 French universities are among the 100 most innovative universities in Europe (Thomson Reuters 2018 ranking). 
France ranks 4th in the world for the number of Nobel Prize winners, including the 2018 Prize awarded to French physicist Gerard Moore and 2nd in the world for the number of Fields medals (the highest award in the world in mathematics).

2) In terms of the number of researchers, France ranks third in the European Union, after Germany and Great Britain.

More than 600,000 people are involved in research activities, 58,000 postgraduates (doctoral students); $(277,600)$ are professional researchers, almost a third $(27 \%)$ of whom are female. Half of the researchers have the right to devote up to $50 \%$ of their time to research in business companies.

3) France has the 4th place in the world for patent applications to the European Patent Office. 16,000 patent applications are filed every year: $22 \%$ comes from small and mediumsized enterprises, $57 \%$ from large companies. More than 2,250 patent applications were filed in 2018 by government research institutions.

4) Institutional research facilities in France.

CNRS (National Center for Scientific Research) is the Europe's top in the ranking of research institutions and ranks \#2 in the world (Nature Index 2017). There are 99 research infrastructures in the country.

At the same time, 2,400 companies, supported by government research for 20 years, created more than 38,000 jobs and a capitalization of 12 bln euros.

5) R\&D funding is 49.8 bln euro or $2.2 \%$ of GDP, which is lower than that of the leading countries.

R\&Ds are implemented both in public and private structures. Public research is carried out mainly in universities and national research organizations, in 3200 own research and joint university units. These structures are major participants in international research, have partners in more than 250 locations around the world: CNRS, Institut Pasteur, Cirad, INRA, INRIA, INSERM, CNES, large research universities.

France is an attractive country for private research, offering a certain set of incentive instruments - a tax credit for research, as well as direct assistance in financing private R\&D, etc. Allocating almost $0.4 \%$ of GDP for public support for private R\&D, France ranks 2 -th place among the OECD countries.

Technological research has been developed: development of accelerometers used in airbags (CEA-Leti), inventions of smart cards (R. Moreno), ultra-low consumption electronic components (SOITEC - CEA), development of TGV, Ariane program, many computer data processing languages, used all over the world.

A number of medical innovations are also the result of French research. Over the past 60 years, 127 international innovations have been presented at French university hospital centers

Turning to some intermediate conclusions, we note that the essence of the transition to the poles of competitiveness, in our opinion, is a departure from the state paternalism of each project at all its stages, the rejection of benefits (including tax), traditional for «first wave» clusters and the transition to decentralized initiation of innovative projects, primarily in the most promising areas of activity that are in demand on world markets. Innovative projects of the poles of competitiveness are financed without state financial resources, or with their partial participation.

The differences between the poles of competitiveness and the clusters of the previous stage are:

- firstly, there is an independent project operator (the pole itself becomes a qualified intermediary that unites the efforts of PC participating organizations, facilitating the search for all types of resources), and there are differences in the scale of the PC (on average, one pole of competitiveness unites more than 127 organizations, although most of them are small innovative enterprises, startups); 
- Secondly, there is a rejection of internal competition. Participants develop partnerships and form partner ecosystems. It is more profitable for large business structures to invest small funds in a startup, risking only small investments if the idea fails, or to cooperate with the laboratories of leading universities-participants of the PC, funded by the state in various projects (IDEX, PIA-1, PIA-2), reducing their own financial risks at the stage of basic and applied research;

- Thirdly, the poles of competitiveness operate based on their own or local initiatives, rather than based on priorities determined in advance by the state. The initiative goes «outside-in», and not vice versa, as it was before in case of clusters;

- Fourthly, innovation funding is mainly provided by participants of the pole of competitiveness, as well as attracted extra-budgetary resources. The PC has greater financial autonomy, since a wide variety of sources are involved in the implementation of projects primarily - venture capital, resources of European investment funds and programs, own funds of the pole participants, as well as state budget sources, especially within the framework of allocated state priorities (aerospace, biomedical and other projects).

Digital technologies give all the processes that take place in the implementation of an innovative project a special cartoon effect, repeatedly speeding up the progress from the idea to its implementation, turn into a powerful factor of production. Based on the use of digital technologies, smart cities are becoming increasingly widespread, as well as many socioeconomic projects to localize the production of innovative products and technologies that give impetus to the development of territories where PCs operate.

Next, the most developed stage of cluster development was the promotion of technopolises (technoparks) that were developing in parallel with them. They appeared in the 70 s of the twentieth century, marking a new era in the industrial policy of many countries.

Technopolises are divided into two types: multipurpose for the global economy (such as Sophia Antipolis in France, Silicon Valley in the United States) and specialized (biotechnologies, space technologies, aviation, and shipbuilding, cosmetology). Thus, Technopolis Sophia Antipolis is a space of globalization on the Cote d'Azur, which is developing in accordance with global markets. Specialized technopolises are developing along with multipurpose technopolises - their life cycle is much less than that of multipurpose ones. Common technopolises are based on cross-technologies, long cycles, with upward diversification, and they are therefore less sensitive to crises. Technopolises in any specialization are the place of cluster development. [5]

Currently, the International Association of technoparks includes about 400 members representing 70 countries. These are not all existing technology parks. Nowadays, there are more than 700 of them in the world, including $42 \%$ in the United States, 34\% in the European Union and $11 \%$ in China. The remaining $13 \%$ are accounted in all other countries of the world.[6]

Following the example of California's Silicon Valley, well-known technopolises have appeared in Japan, Malaysia, Singapore, and Sweden. The most famous in France is the science-city - Sophia Antipolis.

\section{Conclusions}

Here is a generalized experience of Grand Paris and Cote d'Azur universities in the implementation of the results of R\&D and the development of the poles of competitiveness (the connection between science, education, territories, megacities)

Grand Paris is an interesting case of a large-scale project in the implementation of which cluster technologies played an important role. The project started in 2007 at the initiative of the then President of France, Nicolas Sarkozy. The idea of the project is to turn Paris and its 
metropolitan area (Ile-de-France) into a modern world-class metropolis of the 21 st century, which:

- creates a favorable living environment for its inhabitants, equalizes the level of social and economic development of all included territories, and also stimulates a sustainable growth of the entire agglomeration;

- carefully preserves culture, historical values, actively develops, but at the same time fulfills obligations under the Kyoto Protocol when constructing modern housing and business offices, improves transport accessibility between the center and the periphery, improves the environmental component, preserves the green belt and protects the environment

The most important characteristics of Paris and Ile-de-France are:

- a world-class hyper-centralized agglomeration that has expanded geographically around Paris and has nearly $12 \mathrm{mln}$ inhabitants. Currently it positions itself as one of the leading economic regions in Europe as a whole;

- the capital of France with a limited area of the territory, but with one of the highest urban densities in the world and strong demographic growth;

- $\quad$ high concentration of economic, tourist, cultural and social life in Paris;

- powerful traffic flows from home to work and vice versa, converging in Paris due to the location of the transport network, an urgent need to connect peripheral cities with each other;

- $\quad$ the city ring road that surrounds Paris, making a clear demarcation with the suburbs.

As a result, the overdue such multi-layered and very complex problems had to be solved. The project started in 2007, 10 teams of international level were involved: architects, urban planners, interdisciplinary specialists. In 2010, Parliament adopted Law No. 2010-597 of June 3, 2010 on Grand Paris, which has been successfully implemented to date.

The implementation of such an ambitious large-scale project became possible due to creation and development of competitiveness poles and large clusters as network structures uniting public and private research structures, prestigious universities, promising enterprises and firms in the Ile-de-France agglomeration.

The Grand Paris project is based on the creation of 7 cluster to increase competitiveness, which operate on the basis of CDT - territorial development agreements with local authorities:

1) The Saclay Plateau Reasearch and Innovation: $20 \mathrm{~km}$ south-west of Paris, the highest concentration of higher schools in this cluster (HEC, Polytechnique, ENSAE, Centrale, Agro, Telecom Paristech, etc.), prestigious scientific institutions (CEA, CNRS) and since 2014 the several universities have merged to create Paris-Saclay University. In 2027, the RER 18 metro line will be launched for the Saclay cluster.

2) The International Trade and Events Cluster of Roissy - Charles de Gaulle: $30 \mathrm{~km}$ north of Paris, the cluseter includes the leading French airport platform Roissy-Charles de Gaulle and the largest European business airport Le Bourget. The following major projects are being implemented in this territory: the international congress center, the European highspeed freight transport project "Carex","Aéropolians", which will ensure the development of an area of 200 hectares, the Europa City retail and leisure project supported by Immochan and the Chinese company Wanda with more than 3 bln euro investment. This cluster will be served by the future Metro line 17 between 2027 and 2030.

3) The Life Sciences Cluster in Villejuif-Evry (Santé Villejuif-Evry): located from Villejuif to Evry, it should promote the emergence of a world-class cluster. It includes 4 engineering schools, 17 CNRS research laboratories and 4 hospitals, the Gustav Russi Institute included and has almost 35,000 students and 8,500 researchers. The Interdisciplinary University's School of Health will strengthen the center in Villejuif. Health R\&D activities extend to Evry through Genopole, the first center in Ile-de-France specializing in research in biotherapy and genetics. It brings together more than 70 companies 
from this sector and 21 research laboratories, organized based on the Center of Hospitals of the South of Ile-de-France. The cluster will be served by metro lines 14 and 15 from 2024.

4) Saint-Denis Plaine Commune Creation Cluste: the cluster covers the towns of SaintDenis, Saint-Ouen, Aubervilliers, Epinay-sur-Seine, La Courneuve, Pierrefitte, Stains, Villetaneuse and L'Ile-Saint-Denis and is located around the Cité du Cinéma (14 film sets and more than 50 television studios), the studios of Plaine Saint Denis, a large university center and large companies. Numerous projects have been launched within the cluster, which will also host the future Olympic village. The cluster is already well served by several RER and metro lines and from 2024 there will be 4 more new GPE lines (14, 15, 16 and 17).

5) La Défense' finance district: Europe's largest business district is the headquarters for many major banks and financial institutions. The business district is undergoing reconstruction and construction of new modern towers. Located close to Paris, it has good transport accessibility, plus there will be a new metro line 15 in 2030.

6) Le Bourget's Airspace cluster: located $13 \mathrm{~km}$ north of Paris, it includes towns of Blanc-Mesnil and Bonneuil-en-France. It is Le Bourget Airport that provides the air navigation orientation of this cluster, where the airshow takes place, and a new Airbus Hélicopters facility has been created in the $60,000 \mathrm{~m}^{2}$ campus in Dugny. Le Bourget will also host some of the Olympic venues. The cluster is served by RER B, and will be reinforced by metro lines 16 and 17 from 2024.

7) The Sustainable City Cluster around Cité Descartes: the cluster, located on the Seine and Marne rivers, starches across the new town of Marne-la-Vallée, from the Cité Descartes to the Val de Europa sector. The Cité Descartes brings together research laboratories and high schools, with about 15,000 students and 3,000 university researchers, and represents $25 \%$ of the national research on sustainable urban development. Since the launch of the cluster, the FCBA Institute of Technology (wood sector) and the Efficiency (Urban Energy Efficiency R\&Dt Center) have also been established. Disneyland Paris and Pierre \& Vacances have joined forces to create the "Nature Town", an ecotourism destination $6 \mathrm{~km}$ from Disneyland. Transport - RER A, in Marne la Valais there will be a new line 15 in 2024 and line 16 in 2030.

Technopolis on the Cote d'Azur, created with public and private funds by Pierre Laffitte in 1970-1985, is still one of the most successful example of cluster policy implementation to date, despite periodic economic crises, its development has been on the rise for more than 35 years, Technopolis «earns» more than the entire Cote d'Azur with all the tourist attractions, hotels, restaurants combined. What is its secret? Why its development is on the rise even in times of traditional economic crises?

In our opinion, the secret of technopark's sustainability is that its founders managed to capture the main promising trend of global development - digital technologies - and attract the world's «trendsetters» in this area to the South of France. The technopark is a home for a number of major European and international organizations operating in the field of digital technologies (for example, the European headquarters of the World Wide Web Consortium (W3C), which develops standards for the Internet, the European Telecommunications Standards Institute (ETSI), The National Institute for Research in Computer Science and Automation INRIA (Institut national de recherche en informatique et en automatique), dozens of divisions of major international companies that work in the most high-tech markets in the world (EURECOM, IBM, etc.).

One of those who introduced the ideas of Technopolis on the Cote d'Azur - an associate of Pierre Laffite - Dominique Fache, who knows Russia well. He worked in our country. As a specialist in cluster policy, Fache offers interesting ideas for creating a technopolis not on the American, but on the French model and in the Russian Crimea. «Crimea can become an innovative center of Russia's development - a technopark of the future, and the crisis can help it in this», says Dominique Fache. 
The successful experience of interaction between educational centers and research laboratories of universities in France with municipalities and business structures in the territories within the framework of the poles of competitiveness demonstrates, in our opinion, a very constructive experience of a non-competitive policy of trilateral cooperation. [8] This policy is based on the logic of partnership, not competition between the structures that make up the cluster.

The French experience testifies to the birth of new forms of industrial policy that successfully implement innovations in a country where the educational and scientific potential is competitive for the world community. It is very important for its implementation in modern Russia.

\section{References}

1. H. Etzkowitz, Tech. An. \& Str. Man., 20, 653 (2008)

2. J. G. Wissema, Delft: Ed. El. Pub, 252 (2009)

3. M. E. Porter, Bost.: Harv. Bus. Sch. Pr., 485 (1998)

4. L. Renou, Thés.: Sci. pol. (2016)

5. D. Bretones, Vie \& Sciences de l'Entreprise, 185/186, 189 (2010)

6. V. Toporkov, Gazeta.ru (2014)

7. Vers une loi de programmation pluriannuelle de la Recherche, https://cache.media.enseignementsup-recherche.gouv.fr

8. E. Ponomarenko, A. Oganesyan, V. Teslenko, Intern J of Econ Pol in Emerg Econom 2(4), 391 (2019) 